\title{
Matrix isolation study of reactive o-quinoid compounds: Generation, detection and reactions
}

\author{
Hideo. Tomioka \\ Chemistry Department for Materials, Faculty of Engineering, \\ Mie University \\ Tsu, Mie 514 Japan
}

\begin{abstract}
A series of o-quinoid compounds are generated by photolysis of phenylcarbene and phenylnitrene precursors bearing appropriate functional groups at the ortho position in an argon matrix at $10 \mathrm{~K}$ and are analyzed by IR and UV/vis spectra. Attempts to convert these quinoid compounds to their valence isomers show that photointerconvertibility is possible only with the quinone methide system. Experimental IR spectra of the observed products are shown to match quite well with the theoretical frequencies calculated by ab initio method. Optimized geometries and energies of the quinoid compounds and their valence isomers are also calculated and are employed to interprete the observed dependence of the reversibility between the isomers on the structure.
\end{abstract}

\section{INTRODUCTION}

o-Quinoid compounds (A) have been invoked as highly reactive molecules in a variety of chemical reactions and have been shown to have potential synthetic utility (ref. 1). Another interesting aspect of these molecules lies in their isomerization between benzo-condensed four-membered heterocyclic ring systems (B). Recent attempts to characterize these species by direct spectroscopic observation coupled with theoretical calculation have began to unfold their nature. While a relatively variety of o-quinoid isomers have been generated and characterized, little is known concerning the strained benzenoid form. The stability of the closed isomer very much depends on the nature of element, and, so far, only derivatives with at least one substituent being $\mathrm{CH}_{2}$ have been isolated (ref. 2).

\section{Scheme I}<smiles>[Y]=C1C=CC=CC1=[V]</smiles>

A

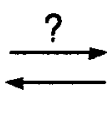

B

In this paper, we wish to report our research along this line where we generated a series of new o-quinoid compounds by photolysis of phenyl azides and diazomethanes carrying appropriate substituents at the ortho position and characterized not only by matrix isolation technique but also by theoretical studies in terms of the valence isomerization.

\section{PHOTOLYSIS OF PHENYL AZIDES HAVING 0-HYDROXY AND AMINO GROUPS}

\section{(A) o-Benzoquinone imine}

Irradiation ( $\lambda>370 \mathrm{~nm}$ ) 2-hydroxyphenyl azide (1) matrix-isolated in an argon at $10 \mathrm{~K}$ resulted in the formation of three products. The two products showing characteristic absorption bands due to carbonyl group were assigned to $E$ - and $Z$-mixture of 6-imino-2, 4-cyclohexadien-1-ones $(3)$, which must be formed as a result of 1,4 - $\mathrm{H}$ migration in photolytically generated 2 -hydroxyphenylnitrene (2), while the remaining product exhibiting the bands due to cumulenic bond was assigned to 6-imino-1, 3, 5-hexatrien-1-one (4) 
which should be produced by ring-opening of 3 upon photoexcitation. The assignments are supported by agreement of the observed IR spectra with the calculated frequencies for 3 and 4 at $H F / 6-31 G^{* *}$ level of theory. The calculations indicate that the closed isomer (5) lies in true energy minima on the corresponding potential energy surface and that this isomer is less stable than the ring-opened structures (3) by 56 $\mathrm{kcal} / \mathrm{mol}$. Control experiments showed that all of those products were photointerconvertible under these conditions. Thus, irradiation of the initial photomixtures containing all the photoproducts with light at $\lambda>420 \mathrm{~nm}$ resulted in the disappearance of the bands due to $E-3$ and 4 and in the concurrent growth of the bands due to Z-3. Irradiation of the mixture containing Z-3 as major component with light of $\lambda>390 \mathrm{~nm}$ and $>370 \mathrm{~nm}$ reproduced the IR bands ascribable to $E-3$ and 4 , respectively.

The optimized geometries of both isomer of 3 are planar and have o-quinoid structure. The $Z$ isomer is calculated to be more stable than the $E$-isomer by $6.6 \mathrm{kcal} / \mathrm{mol}$. Inspection of the structure suggested that this stabilization is caused by the hydrogen-bonding between imino hydrogen and carbonyl oxygen. At least four rotational isomers are possible for 4. Calculations of total energies for each of the stationary points indicate that the stability decreases in the order of $E, E>E, Z>Z, E>Z, Z$ with the energy difference of less than $5 \mathrm{kcal} / \mathrm{mol}$.

Finally, for the azetine (5) do the calculated frequencies appear not to match the experimental data, confirming that this isomer was not produced. Thus, the predicted relative energies as well as the calculated frequencies of the proposed intermediates in the tautomerization of $\mathrm{C}_{6} \mathrm{H}_{5} \mathrm{NO}$ molecules fully support the assignments based on the experimental observations.

\section{Scheme II}

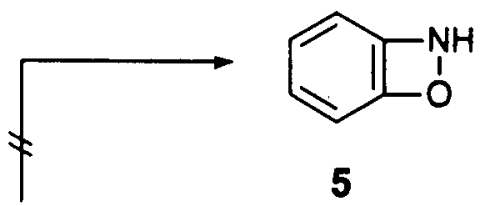

(56.3)

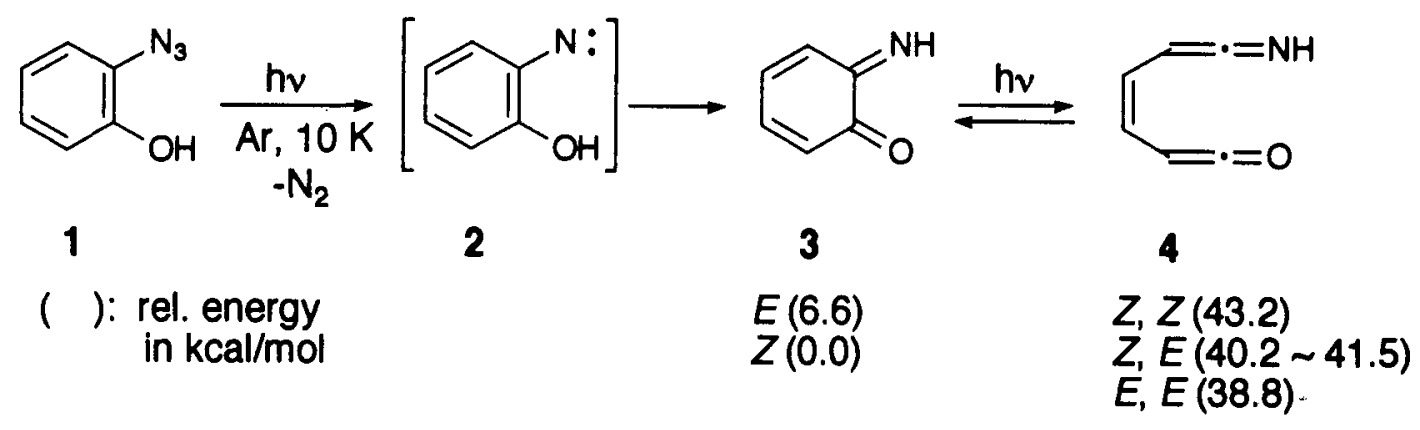

\section{(B) o-Benzoquinone dilmine}

Photolysis $(\lambda>350 \mathrm{~nm}$ ) of 2-aminophenyl azide (6) in argon at $10 \mathrm{~K}$ resulted in the formation of three products which were interconvertible upon irradiations. Disappearance of the absorption of amino group coupled with the absence of cumulenic band suggested 1,2-diimino-3, 5-cyclohexadiene (8), expected to be formed as a result of 1, 4- $\mathrm{H}$ migration in the photolytically generated nitrene (7) as the most plausible structure. Thus, the vibrational frequencies for three isomers of 8 were calculated at HF/6-31G ${ }^{* *}$ level of theory and compared with the experimental values, which clearly showed that the calculated frequencies for $E, Z-, Z, Z-$, and $E, E-8$ match quite well with the observed spectrum.

The optimized geometries of those isomers suggest that both the $E, E$-and the $E, Z$-isomers are planar while non-planar structure is optimized for the $Z, Z$-isomer. The $E, Z$-isomer is calculated to be the most stable isomer while the $E, E$-isomer is the most unstable one lying $7.3 \mathrm{kcal} / \mathrm{mol}$ higher in energy than the $E, Z$ isomer. It is probable that the planar $E, Z$ isomer is stabilized by a hydrogen bonding while the destabilization of the $E, E$ isomer is caused by the repulsive interaction of the lone pairs at the nitrogen atoms. The ring-opened isomers (9) which were not observed experimentally were calculated to be more than $40 \mathrm{kcal} / \mathrm{mol}$ unstable than the diiminedienes (8). The order of the stabilities among the three possible rotamers are $E, E>E, Z>Z, Z$ with the energetic differences of less than $7 \mathrm{kcal} / \mathrm{mol}$, and only the most stable $E, E$ isomer has a planar structure. On the other hand, for the ring-closed isomers $(10)$, which were also not observed, the two isomers were calculated, where $\mathrm{C}_{2}$ symmetrical $E$-isomer is more stable than the $\mathrm{C}_{5}$ symmetrical Z-isomer by $6.3 \mathrm{kcal} / \mathrm{mol}$. 


\section{Scheme III}

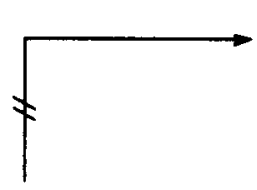<smiles>c1ccc2[nH][nH]c2c1</smiles>

10

$E(29.7)$

$Z(36.0)$<smiles>Nc1ccccc1N</smiles>

6<smiles>Nc1ccccc1N</smiles>

7<smiles>C=C(C)C</smiles>

8<smiles>N=C=C/C=C\C=C=N</smiles>

9

( ): rel. energy in $\mathrm{kcal} / \mathrm{mol}$

$E, Z(0.0)$

\section{PHOTOLYSIS OF PHENYLCARBENE PRECURSORS BEARING O- HYDROXY AND AMINO GROUPS}

\section{Benzoguinone methides}

Irradiation $(\lambda>254 \mathrm{~nm}$ ) of phenol (11) bearing "masked" diazo function at the ortho position in argon at $10 \mathrm{~K}$ produced strong absorption band due to styrene indicating that the desired decomposition generating carbene 12 took place even at this low temperature. Although the product absorption bands were largely overlayed by styrene absorption, the bands descrete from styrene are in agreement with that calculated for benzoxetene (13) in terms of the position and intensities. The photodecomposition of 11 ceased before reaching completion probably due to overlapping absorption of the incident light by styrene and hence attempts to check the possibility of conversion of 13 to 14 were unsuccessful.

Photolysis $(\lambda>254 \mathrm{~nm}$ ) of isophthalide (15) in argon at $10 \mathrm{~K}$ generated $\mathrm{CO}$ and a product exhibiting carbonyl stretching absorption band, which was assigned to quinone methide (14) based on the direct comparison with that reported as well as the calculated frequencies for 14. Irradiation of the matrix containing 14 with light of $\lambda>350 \mathrm{~nm}$ produced the bands due to 13 , which regenerated 14 upon irradiation with shorter-wavelength light $(\lambda>254 \mathrm{~nm})$. Thus, photochemical interconversion between 13 and 14 was shown to be attained in this case. The calculations indicate that the energy difference between the two isomers is less than $5 \mathrm{kcal} / \mathrm{mol}, 14$ being more stable. The optimized geometries $\left(\mathrm{HF} / 6-31 \mathrm{G}^{* *}\right)$ suggest that both isomers are planar and 14 has o-quinoid structure.

\section{Scheme IV}<smiles>O=C1Cc2ccccc2O1</smiles>

15

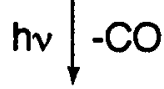<smiles>Oc1ccccc1/C=N/N1CC1c1ccccc1</smiles>

11<smiles>C=Cc1ccccc1</smiles><smiles>Oc1ccccc1C=Cc1ccccc1</smiles>

12 
The results are similar with that observed for 2-aminophenylcarbene (17) which also produced both benzoazetine (18) and o-iminoquinonemethide (19) as a photoequilibrating mixture. The energy difference between the two isomers is less than $7 \mathrm{kcal} / \mathrm{mol}$, the closed isomer (18) being more stable in this case (ref. $3)$. The $E$-isomer of $\mathbf{1 9}$ is almost completely planar, while in the $Z$-isomer, the steric interaction of the inwards pointing hydrogen atoms leads to a twisting of the $\mathrm{NH}$ and $\mathrm{CH}_{2}$ groups of $22^{\circ}$. Benzoazetine (18) has a benzenoid structure with the four-membered ring only slightly twisted (ref. 3 ).

\section{Scheme V}<smiles>N#Cc1ccccc1N</smiles>

16

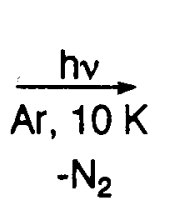

17<smiles>CC1C[C]c2ccccc2N1</smiles>

7<smiles>c1ccc2c(c1)CN2</smiles>

18

(0)

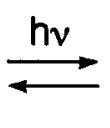

19<smiles>C=C1C=CC=CC1=N</smiles>

$Z(6.4)$ $E(5.8)$

\section{CONCLUSION}

We have shown that phenylcarbenes and phenylnitrenes having appropriate functional groups at the ortho position can be very promising and clean precursors for a series of reactive ortho quinoid compounds especially in the matrix conditions since the precursors undergo decomposition very efficiently upon photoexcitation even under these conditions to eliminate nitrogen which is spectroscopically invisible and generated divalent species also undergo very efficient $\mathrm{H}$ migration reaction again even at this low temperature to form the expected o-quinoid compounds. It has also been shown that the theoretical calculations exhibit the greatest powers for characterizing the intermediates generated in the cold window. Thus we are not only able to generate and characterize some of the hitherto unknown o-quinoid compounds, but also able to interprete the origin of the reactivity difference among those intermediates. Whole aspects of the structure-reactivity relationship of this interesting molecules will be disclosed by the continuous studies which are under progress.

\section{REFERENCES}

1. See for a review, "Comprehensive Organic Synthesis" Ed. by B. M. Trost, I. Fleming, Pergamon Press, Oxford, 1991, Vol. 5, pp 385-396.

2. For X = S (a) K. Kanakarajan, H. Meier, J. Org. Chem., 48, 881 (1983). H. Meier, H-L. Eckes, H-P. Niedermann, H. Kolshorn, Angew. Chem., Int. Ed. Engl., 26, 1046 (1987). M. Schmidt, H. Meier, H-P. Niedermann, R. Mengl, Chem. Ber, 123, 143 (1990). H. Meier, D. Gröschl, Tetrahedron Lett., 36, 6047 (1995).

For X = O (a) G. C. Paul, J. Gajewski, J. Org. Chem., 58, 5060 (1993). P. D. Garduer, H. Sarrafizader, R. R. L. Brandon, J. Am. Chem. Soc., 81, 5515 (1959). C. L. Mclntosh, O. C. Chapman, J. Chem. Soc., Chem. Commun., 771 (1971). M. Consuelo Jiménez, F. Márquez, M. A. Miranda, R. Tormos, J. Org. Chem., 59, 197 (1994). H. Meier, H-P. Schneider, A. Rieker, P. B. Hitchcock, Angew. Chem., Int. Ed. Engl., 17, 121 (1978).

For $X=N$ (a) M. Letulle, P. Guenot, J-L. Ripoll, Tetrahedron Lett., 32, 2013 (1991). G. PfisterGuillouzo, F. Gracion, A. Senio, M. Letulle, J-L. Ripoll, Tetrahedron Lett., 33, 5753 (1992). G. Smolinski, J. Org. Chem., 26, 4108 (1961). E. M. Burgess, L. McCullagh, J. Am. Chem. Soc., 88, 1580 (1966). S. Murata, T. Sugawara, H. Iwamura, J. Am. Chem. Soc., 107, 6317 (1985).

3. J. Morawietz, W. Sander, M. Trảubel, J. Org. Chem., 60, 6368 (1995). 